\title{
Mapping Land Cover Determinants of Malaria In Obio Akpor Local Government of Rivers State, Nigeria
}

\author{
Ayo Vivienne Obianuju, Andrew Obafemi , and Ogoro Mark \\ Department of Geography and Environmental Management, University of Port Harcourt, Port Harcourt, \\ Nigeria.
}

\begin{abstract}
Malaria is a very common disease in most of the tropical regions and its spread is caused by mosquito's presences favoured by topography and land cover that allows potential breeding and transmission. Primary data was obtained from focal group discussion while the secondary data employed was obtained from Landsat imagery 30 by 30 meter resolution employed for the study in the geographic information system environment. Topographic information of the region was also derived from the srtm data and employed for the analysis. Findings revealed that there is much awareness of the presence of malaria spreading mosquitoes and environment in the local government favoured by presence of forest land cover and poor / blocked drainage. Finally from the analysis of land cover and topography of the study area, potential breeding sites for mosquitoes are clustered and cut across the entire Local Government. The study recommends that potential breeding sites should be fumigated to mitigation the pace of mosquitoes breeding and spread in the study area
\end{abstract}

Keywords: Malaria, Breeding, Imagery, Mosquitoes, environment

\section{INTRODUCTION}

Malaria is serious and most common disease in Africa and it is known to affect people in the tropical region. The parasite is known to be caused by mosquitoes as a major carrier and is an extreme causation of fatality and morbidity in the world today. Malaria spread and presence is influenced strongly by environmental factors therefore it is endemic in the world's sub-tropical and tropical regions (European Molecular Biology Organisation, 2004). The outbreak of the vector borne disease usually requires intermittent agents for possible transmission. This has created a heavy burden on the human race impeding economic productivity and development. Traditionally, controlling the spread of the disease is becoming a problem hence the modern control is seen as the most efficient way of controlling the spread of the disease this is because vectors control are usually achieved using extensive chemical insecticides which Ahmed in 2011 affirmed were quite successful in curbing the disease concerned (malaria outburst). However, the wide spread use of these chemicals in every household and across every section of the environment is highly stressful on the environment causing undesirable side effect on the complex tropical environment and habitats affecting a wide spectrum of non-targeted organism which play a very vital role in our ecological cycle (Rohani et al 2002). Therefore, instead of applying chemical insecticides across the environment and in every household, there are new tools such as the Geographic Information System (GIS) technologies which allows or make possible the mapping of potential larval habitats in an environment (Minakawa, 1999). The use of the GIS tools will allow the forecasting of potential malaria dominant and transmission zones by delineating potential breeding habitats for malaria vectors in an environment. This has made the utilization of satellite imagery in the remote sensing platform and the Geographic Information System (GIS) environment to delineate areas of the environment that allows the habitats of malaria using functions or criteria such as topography, drainage and land cover to show the potential breeding site for mosquitoes breeding and transmission. The topography of a place plays a very vital role as it does not allow or allow the retention of water on the surface to make for the breeding of mosquitoes. Landuse on the other hand defines the level of water stagnation in the environment, though, sometimes subject to its population density, especially in relation to agricultural land uses. With reference to the World Health Organisation (WHO), 3.3 billion persons approximately which are almost $50 \%$ of the population of the world are exposed to malaria. Annually, the World Health Organisation recorded that out of this population exposed 250 million come in contact to the disease in which 1million die from that contact. The forest region inhabitants are the most vulnerable occupying 109 countries in which 35 of these countries account for $98 \%$ of Malaria cases world wide

Recently, the use of Geographic Information System has been very pronounced as an important aspect or component of projects in the area of public environmental health. Epidemiologists have in older times used maps to examine relationship between location, environment and disease occurrence (Carter, 1992). 
This is because controlling malaria is crucial if Nigeria wants to achieve its millennium development goals one of which is reducing the incidence of malaria related or caused disease across the country which according to the National Malaria Indicator Survey Report in 2010, the following was gathered: In Nigeria, about three hundred thousand $(300,000)$ people die yearly of this disease called malaria. Of this population, children sum up to two hundred and fifty thousand $(250,000)$ of the population of deaths. This position represents $10 \%$ and $30 \%$ of Maternal and Childhood deaths respectively. This has resulted to a loss of about 1 billion dollars annually. Hence, from the tropical situation, environmental factors which influences about 70-90 $\%$ of malaria risk as the environmental conditions to include land cover, hosts and allows abundance and survival of vectors. This trend motivated the WHO to explore for methods or techniques accommodating environmental factors and spatial technology in systematically and regularly monitoring environmental conditions of communities in order to rid them of malaria. In the past year (30) there is a very wide notice among patients that malaria parasite are becoming resistant to a number of malaria drugs (Wongsri, Chanalai, Pickard, Wernsdorter, Meshnick 2002). This is alongside the resistance of insecticides by most mosquitoes (Zaim \& Gvillet, 2002) With this level of resistance of insecticides by mosquitoes across the globe there is widespread of malaria parasite among people. This has shown that the evolution against malaria will be very difficult to halt and therefore the use of malaria drug and insecticides would end up being a short term approach to malaria control. It is therefore necessary to consider the role of environmental management and geospatial approach to malaria control. This is because environmental management approaches will reduce the level of dependency on anti malaria and insecticide in the control of malaria. Environmental management as a method of control of malaria parasite involves the reduction in the number of mosquitoes breeding habitats. This can be achieved by controlling mosquitoes at the aquatic stage which involves the chances of eliminating the chances of the environment harbouring suitable water bodies that allow mosquitoes to lay their eggs which enhance the maturity of the aquatic stage. Hence, spatial-temporal information on the land cover situation will be very fruitful for early detection and timely response to disease management especially malaria. The main thrust of this study is to assess potential mosquito breeding sites in Obio Akpor Local Government Area using a geospatial technique in delineating land cover that are potential breeding sites for mosquitoes and the enhancement of vulnerable to malaria disease.

\section{STUDY AREA LOCATION AND EXTENT}

Obio Akpor LGA is one of the 23 local governments of Rivers state, found in the south southern part of Nigeria, otherwise called the Niger Delta Region of Nigeria, located approximately between latitude $4^{0} 45^{\prime \prime} \mathrm{N}$ through $4^{0} 56^{\prime \prime} \mathrm{N}$ and longitude $6^{0} 52 " \mathrm{E}$ through $7^{0} 6^{\prime \prime} \mathrm{E}$. It has a general elevation of less than $15.24 \mathrm{~m}$ above mean sea level (Oyegun \& Adeyemo, 1999). It is bounded by Ikwerre LGA to the north, Port Harcourt LGA to the south, to the east, Oyigbo LGA and to the West, Emohua LGA as shown in figure 1. Obio-Akpor, Port Harcourt, and Eleme LGAs, make up the Port Harcourt metropolis which is on a firm ground and about 66km from the Atlantic Ocean (Oyegun \& Adeyemo, 1999).It is one of the major centres of economic activities in Nigeria, and a major city in the Niger Delta said to be the richest LGA in Rivers State. Consequent on rapid urbanization and the rising industrial and commercial growth of the city of Port Harcourt, more goods and services are being made available, thus the springing up of fuelling stations, to meet up with the demand of the growing population arises. Obio-Akpor LGA was formed from the Port Harcourt Local Government Area of Rivers on 3/5/1989. This action was carried out by President I.B. Babangida who was a Military President at the time. It is made up of the Ikwerres and has the LGA headquarters at Rumuodumanya (Mamman, Oyebanji, \& Petters, 2000

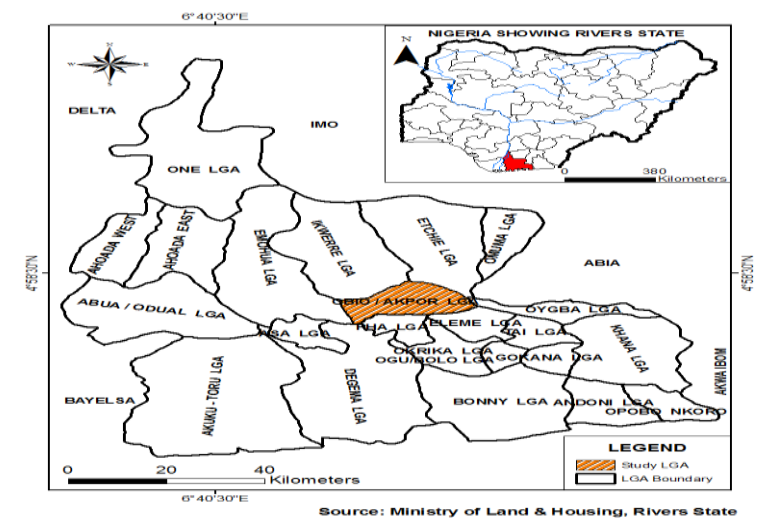

Figure 1. Rivers State Showing Study Area (Obio/Akpor LGA) 


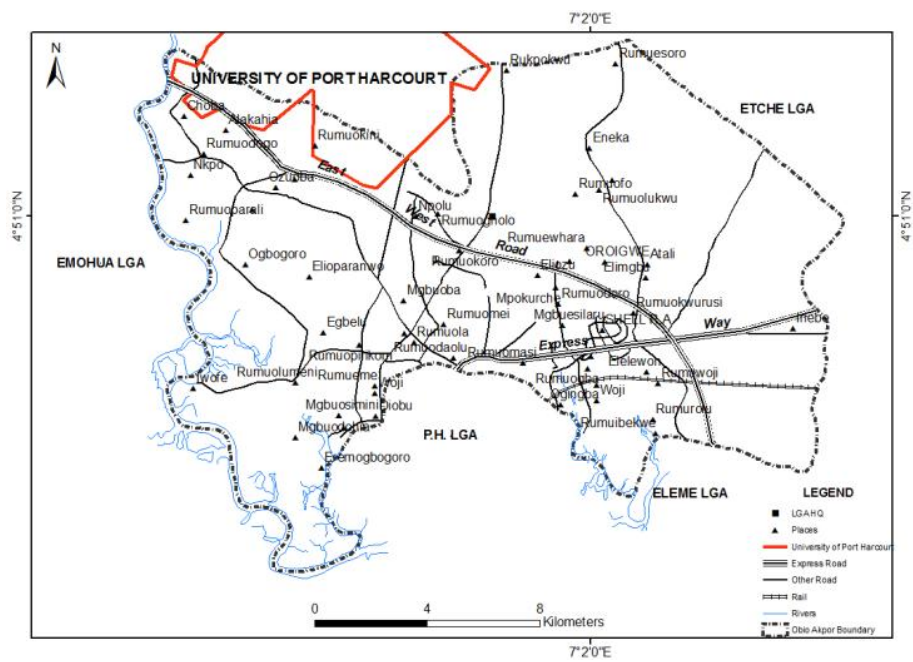

Source: Ministry of Lands \& Housing, Rivers State

Figure 2. Study Area (Obio/Akpor LGA) showing Communities Population

The population size of Obio-Akpor LGA with reference to the 1991 census population of Nigeria, by the National Population Commission (NPC) was put at 283,294 persons, made up of 145,326 males and 137,968 females, which brings the males to $51.02 \%$ and the females to $48.07 \%$ of the total population (N.P.C, 1991).

\section{Geology}

Rivers state, where Obio-Akpor is found, in the Eastern Niger Delta's newborn coastal plain. On its surface are found fluvial sediments making up its geology. The fluvial sediments are made up of the ones transported recently by the River Niger and some other rivers, for example, New Calabar River, Bonny River, and Andoni River. The substances are accumulated as regolith over the burden of about 0metres - 30metres thicknesses are gravels, sands, silts, peat, and clays. The series of deposition alters clays and sandstones which are marginal of marine origin. It grades downwards into marine clays, and its sequence of deposition is massively continental. The most extensive rock type in rivers state is sand while in the riverine areas of the state, mud is found in the areas where there are polluted brackish waters. In shallow pits and bugs, animal and vegetal remains which are the constituents of peat are found. The last of the rock's subsurface is made up of pebbles and gravels settle at the bottom of the channels of the rivers (Oyegun \& Adeyemo, 1999).

\section{Soils}

Soil types in Rivers state can be grouped into three thus:

\section{Fluvial-marine and Marine sediments.}

The wet coastal regions are home to this type of soil. They are characteristically sandy and organic in texture and nature respectively. Some of them are composed of organic matter which is decaying, mixed with mud.

\section{The alluvial soils of the mangrove swamp and;}

This soil type is found in the coastal sediments zone in the northern region of the state. The layer on top is usually brown in colour and rich in organic matter. They are also characterised by offensive and unpleasant odour and are usually salty most often when there are no rains.

\section{Sandy loams and freshwater brown loams}

These types are found in the deltaic regions where freshwater zone is located. More clayed soils and more acidic soils along their slopes formed levees, which are the landforms common in this area (Oyegun \& Adeyemo, 1999).

The soil types in the study area consist of poorly drained silty clay mixed with sand which is classified under the Benin formation (Gobo, 1990). The dry land areas consist mainly of building foundations but proper drainage is needed. The soil classes of Port Harcourt of which Obio-Akpor is a part of can be divided into two broad types, they are:

i. Those derived from the older sediments

ii. Those formed on younger and recent alluviums. 
According to (Oyegun \& Adeyemo, 1999), these groups are further divided into eight classes, represented with letter A-H. The older sediments can be differentiated into the following;

- Non-leached shale and is represented by the letters G and F.

- Leached coastal plain sand under moist forest cover and the letter is E.

Mixed parent material of sandstones and shale, with the letter $\mathrm{H}$.

The old sediments are derived from mixed parent materials. The soils that are derived from the mixed parent materials are well drained. For the F and G soil unit, their fertility is low and this is because they are composed of quartz and kianolite. The soil unit $\mathrm{E}$ is made up of soils that are deep porous and brown in colour usually found on sandy parent materials. It is similar to the $\mathrm{F}$ and $\mathrm{G}$ class but the difference is that the $\mathrm{E}$ is pale in colour due to the amount of leaching going on. The soil unit $\mathrm{H}$ is a mixture of red and brown soils derived from sandstone and shale.

Soils of the Younger Quaternary are differentiated into:

I. Freshwater alluvium which is usually located in the flood plains of the river.

II. The coastal intertidal flat of coastal swamps which includes what is called beech rich sand.

III. Soils of the mangrove swamps.

IV. Soils in depression.

\section{RELIEF AND DRAINAGE}

Relief could be defined as the undulating nature of a place, that is, the high and low lands which characterize a place. Drainage, on the other hand, can be said to be the embodiment of water bodies such as lakes, streams, rivers, etc which are present in a place (Oyegun, 2014).The relief of Port Harcourt city to which Obio-Akpor is a part of falls within the Niger Delta relief system, one of the seven relief systems of Nigeria. These are based on the land units or common land from assemblages. The Niger delta is a vast area of alluvial deposits stretching from Forcados River in the west to Bonny River in the east; a distance of about $350 \mathrm{~km}$, from its apex to the sea, the delta is about $150 \mathrm{~km}$ long. It covers an area of about $10,000 \mathrm{~km}^{2}$ most of which is made up of swamps. The Niger divides up into many tributaries between which are a number of islands of solid, red earth which trend north-south. These islands have a mean height of about $20 \mathrm{~m}$ from the only firm, dry land and are favoured for settlements (Kingsley, 2002; Oyegun \& Adeyemo, 1999). On the surface, the area of study has its structure belonging to the recent Niger Delta Sedimentary formations, which has coastal plains that are low lying, dominating it. The meters above sea level is below 15.24metres (Oyegun \& Adeyemo, 1999).Generally, the land surface of Rivers state slopes gently in the North West (NW) and South East (SE) direction. The state's northern quadrants characteristically have planes rolling gently. The southern part has sand bars, mud flats and swamp tidal basin predominating in that part of the state (Oyegun \& Adeyemo, 1999).The lower Niger Delta floodplain is more prone to annual river flooding because of the clay and silt in its foundation. In the North East, there is an upward appreciation to about 45 meters and more than 9meters in the north-eastern part where the zones of beach ridges are found to the south west. The geomorphic trend's structure southwards and northwards shows a pattern of a flood plain which is homoclinical, having swamp basins that are shallow and hug back ridges that are small, which break in many places. Numerous channels of water in the fresh water zone have their borders as levees which are natural, and are of immense topographic importance and also economically relevant to the people of the locality. The drainage characteristic of the region is low-lying with much surface water which is tidally flooded seasonally.

The drainage systems in the state are mainly two which are:

i. Fresh water which has their water origin is fully or partly from inside the lowlands of the coastal region.

ii. The bottom part of the state where systems of tides are restricted to. (Mamman, et al., 2000).Rivers found in the study area possesses typical values of $1.5 \mathrm{~km}$ and the ratios of sinuosity as $1: 9$, which indicates that the channels which meander are turbulent. There is an increase in these systems downstream generally. The increase is notable in velocity and width. This is very notable in the zones of fresh water which the New Calabar River drains. Prominently, valley side slopes and riverbank levees which are highly eroded, and also experience high accretion, and are very gentle are notable (Mamman, et al., 2000). The entire relief is made up of sand bars and coastal plains that are rolling gently. The drainage of the area is controlled structurally by the shore zone dendritic pattern of the lowland of the coast, in which its tributaries branches irregularly at any angle in any direction. Due to these characteristics, it is most likely near sedimentary rocks that are horizontal (Oyegun \& Adeyemo, 1999).The pattern of the network in the area does not exactly fit into the trellised drainage pattern neither does it fit into the dendritic pattern either. The numerous rivers in the study area, all empty into the Atlantic Ocean (Oyegun \& Adeyemo 1999).The entrance to the creek and system of the river, for example, the Bonny and the New Calabar river systems allow the river to empty their waters into the Atlantic ocean and serves as inlets of large quantities of ocean wide and there is very wide intertidal flat traversed by several creeks (Oyegun \& Adeyemo 1999). 


\section{WEATHER AND CLIMATE}

Weather is the condition of the atmosphere of a geographical location at a particular time while climate is the synthesis of weather conditions of a period of about 30 years. It does not just deal with averages of weather conditions but the frequency and extremities of weather conditions. The weather system of the study area is basically a result of the main systems of the wind in Nigeria. The south-west winds bring wetness to the state. It passes through Port Harcourt from the month of February to November. The region has its rainy season at this time. The dry period when there is no rain is brought by the north-east trade winds which blow through the area from the months of November to February passing through the Sahara Desert. The two winds meet on water and become the inter-tropical discontinuity while it is referred to as inter-tropical convergence zone on land. Rainfall is on the decrease annually from $4700 \mathrm{~mm}$ to $1700 \mathrm{~mm}$. The decrease is from the northern part of the state. It increases from about $1700 \mathrm{~mm}$ in the extremes of the north to $4700 \mathrm{~mm}$ in the coastal areas. Degema which is found in the northern part has its annual rainfall as $1.862 \mathrm{~mm}$ while in Bonny which is along the coast has it's as $4,689 \mathrm{~mm}$. The rain is sufficient to grow crops all through the year. The average annual number of days of rain is 330 days for the state and $182 \mathrm{~mm}$ for the area of study. This has an average rainfall of 250mm (Mamman, et al., 2000).

The temperatures on highest levels are from $28^{\circ} \mathrm{c}$ to $33^{\circ} \mathrm{c}$ monthly, $17^{\circ} \mathrm{c}$ to $24^{\circ} \mathrm{c}$ on lowest levels monthly. On the general note, the average temperature is $25^{\circ} \mathrm{c}$ to $28^{\circ} \mathrm{c}$ per month. Annually, the mean temperatures record $26^{\circ} \mathrm{c}$ with a slight change of $2^{0} \mathrm{c}$ in the two different seasons (Mamman, et al., 2000). In the area, relative humidity is on the high side. This is due to the amount of rainfall the area receives yearly, with a decrease in the hammerttan season.(Salawu, 1993). The position of the state near the close to the equator makes it have lots of sunshine. It has a very humid tropical climate and hot. However, the volume of solar radiation gotten at the surface is highly brought low mainly due to cloudy nature consequent upon its coastal area. April, March, and February which are the dry seasons of the year record the highest mean maximum daily temperature while rainfall is at its peak in July and September (Oyegun \& Adeyemo, 1999).

\section{Environmental Condition and Malaria Incidence}

About $90 \%$ of the incidence of malaria globally today is mostly found in the Sub-Saharan Africa. This was not the trend in this part of Africa as the number of incidences was most noticed in Asia in the beginning of the 1900s (Kidson \& Indarata, 1998). The incidence of malaria in the Asia region is mostly found in the deltas of the region (Kidson \& Indarata, 1998). The region's approach in the elimination of malaria was mostly the adoption of environmental management approaches. The most widely known method used was draining and filling the swamps as practiced in Klang and Port-Swettenham, Scango (Sandosham, 1959).It is, therefore, obvious that understanding the environmental conditions around settlements could lead to a substantial reduction to malaria incidence. From the above, in a coastal environment, Sundaicus can be contained by the installation of tidal flats which would prevent the inflow of saline water that mostly favours the breeding of mosquitoes. While inland of coastal area Maculatus could be properly controlled by the construction of settlement in a well drained and cleared vegetated area to prevent to prevent the breeding of mosquitoes in such habitat. The presence and intensity of malaria occurrence in a place is a function of many environmental and atmospheric factors which are rainfall, temperature, humidity, vegetal cover and the presence of surface water (Ceccato, Connor, Jeanne and Thompson, 2005).

Rainfall: The ability of malaria to grow and spread over time is a function of the availability of water, most especially clean water for eggs to be laid and developed. Rainfall makes available these water bodies in the tropical environment that will encourage the laying of eggs and development of larvae and in the long run, the spread of mosquitoes (Ceccato, Connor, Jeanne and Thompson, 2005). The increase in rainfall may result in an increase of anopheles breeding sites on one hand and in the other hand, the rainfall if excessive will result in the wiping out of sites of breeding that are small, for example, pools and ditches (Ceccato, Connor, Jeanne and Thompson, 2005).

Temperature: temperature plays a very vital role in both vector and parasite development. For vector, population and the rate of development of the juveniles are related to the temperature, while for the parasites, the temperature at the period of incubation has an exterior effect on it (Lactin et al 1995). This is shown as incubation occurs in lesser days at a higher temperature than colder temperatures while vector development is increased at colder temperatures than warm temperatures (Bouma et al, 1994).

Humidity: the rate at which adult insects which mosquitoes belong survives is in relation to saturation deficit which is derived when the actual water vapour is subtracted possible water vapour pressure given a particular temperature required. 
Surface water: the presence of surface water like pond, lake and other bodies provide the habitat for the breeding of mosquitoes at juvenile stages i.e. the eggs, larvae, and pupae. This, therefore, made for the monitoring of water body presence in small quantity in an environment in order to eliminate the potential of vector breeding there.

Vegetal cover: the presence of vegetal cover and the stage of vegetal growth may to a long run determine the presence of vector in the environment. Also, the state of vegetation provides resting sites for adult mosquitoes and protection of harsh climatic conditions (Beck et al, 1994). The vegetal cover stage, therefore, can be seen to determine the prevalence of the mosquito at every stage juvenile or adult.

\section{Malaria Exposure Mapping}

Mapping malaria exposure in the study area produces information to the people on the occurrence of malaria vector and disease across the geographical space. This will make available maps and pictorial view by identifying subtle patterns in the occurrence of a disease like malaria over space that is sometimes not visible in tabular presentations thereby showing a simple description or a visual summary of geographical community risk to the incidence of malaria. The epidemiology of vector-borne diseases is presently fast changing across the globe as a result of data availability and other faster method of data collection using imageries and GPS. This method of data collection has made for easy field data retrieval and remotely sensed image aided data collection. This method of data collection using imagery has made for the identification and characterization of malaria breeding sites for easy monitoring and mapping of malaria risk sites. GIS was used to develop maps with the aid of aerial photographs of malaria risk areas in Tanzania which made a complete coverage of larvae dominated and risk population for easy control and monitoring (CDCP 2008)Remote sensing imagery has been used for the characterization of the breeding habitats for malaria in Korea republic (Sithiprasasna, Ugsang and Linthieum, 2005) this has made for the integrated use of remote sensing and the GIS technique in successfull demonstrating the relevant of mapping malaria risk in different parts of Africa. GIS and remote sensing tools are the ideal tools for generating base maps and mapping breeding habitat alongside the analysis of areas with high risk of malaria prevalence if combined.

\section{METHODS AND MATERIALS}

The image of the study area will be obtained from Landsat TM Tin image available at the global land cover facility data. This was used to classify the area land cover to obtain a land cover map for the study area. Classified rivers and water bodies' especially stagnant or slow flowing water bodies (wetlands) were delineated extracted and integrated into the ArcGIS environment. Spatial analysis and processes of the derived data were thereafter carried out into WGS 1984 (UTM Zone $32^{\circ} \mathrm{N}$ ) projection from the producer Global Land Cover Facility (GLCF). This made for all pixels on the image to be assigned to the real world coordinate system of the WGS 1984 (UTM Zone $32^{\circ} \mathrm{N}$ ) projection system as the area of intent is Nigeria. A superimposed classification approach will be used in classifying the image pixels to the exact spectral of reflecting ground data. This, therefore, sorted the pixel into a finite number of classes that are individually assigned to data category which was based on their data value in the file. This method makes each pixel that satisfies specific criteria to be assigned to those criteria to which it is identified with or belongs to the entire image was converted to a thematic map using the signature file and maximum likelihood algorithm. The land cover of the study area was delineated via the processed image. The map of the study area was geo-referenced and community position properly identified which was confirmed through ground truthing using the global positioning system (GPS) which was overlaid on the malaria risk map of the study area to show areas that are exposed to malaria in the area. The total land area of classified area in the study area was calculated using the geometry extension of calculating the area in the ArcGIS environment while the spatial distribution of the spatial prone areas was analyzed using the spatial analysis tools in the ArcGIS environment, this would aid to generate hotspots of malaria prone areas. The hypothesis which states that malaria breeding sites in the study area are evenly distributed was tested using the nearest neighbour analysis to show if the potential breeding sites for vectors are random, clustered or dispersed across the study area.

\section{RESULTS AND DISCUSSION OF FINDINGS}

From the focal group discussion was conducted in the communities of the study area which is Obio Akpor LGA. Twenty-nine communities were visited and from the analysis of responses from 29 communities in the study area evaluating the people's perception of the causes of malaria in their locality. The figure 4.1 as shown below reveals their responses during the focal group discussion 


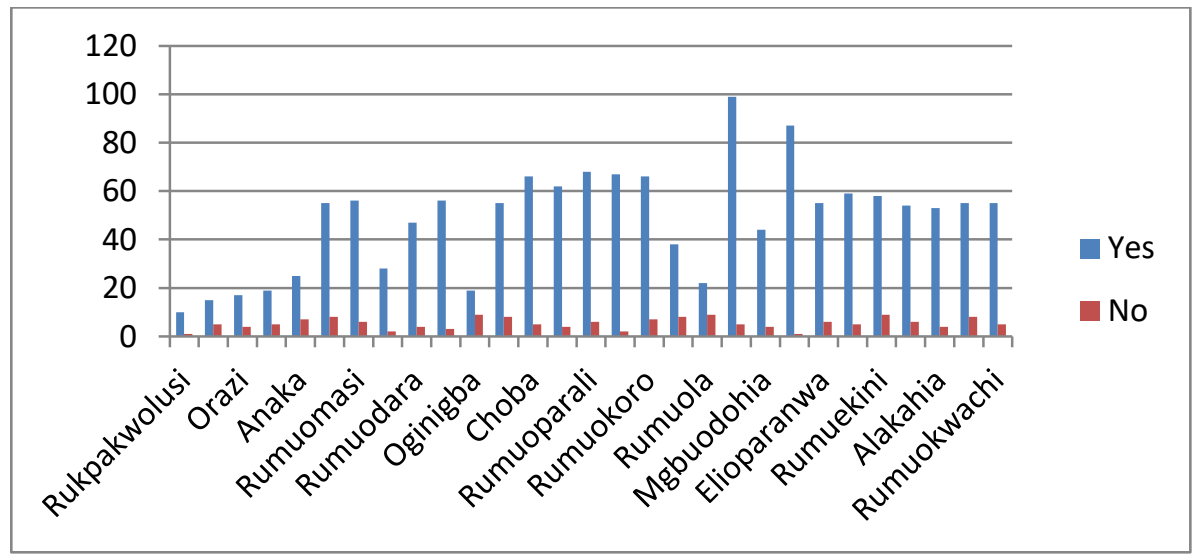

Figure 1 Respondents view on the prevalence of mosquitoes in their communities

From the analysis shown in figure 1, most of the respondents interviewed acknowledged the presence of malaria in their locality. From the figure, over 90 percent of the respondents acknowledged the presence of mosquitoes in their locality which is the major causes of malaria among them, very few less than 10 percent of the population were of the opinion that mosquitoes are not very pronounced in their locality and therefore cannot be said to be the major causes of malaria.

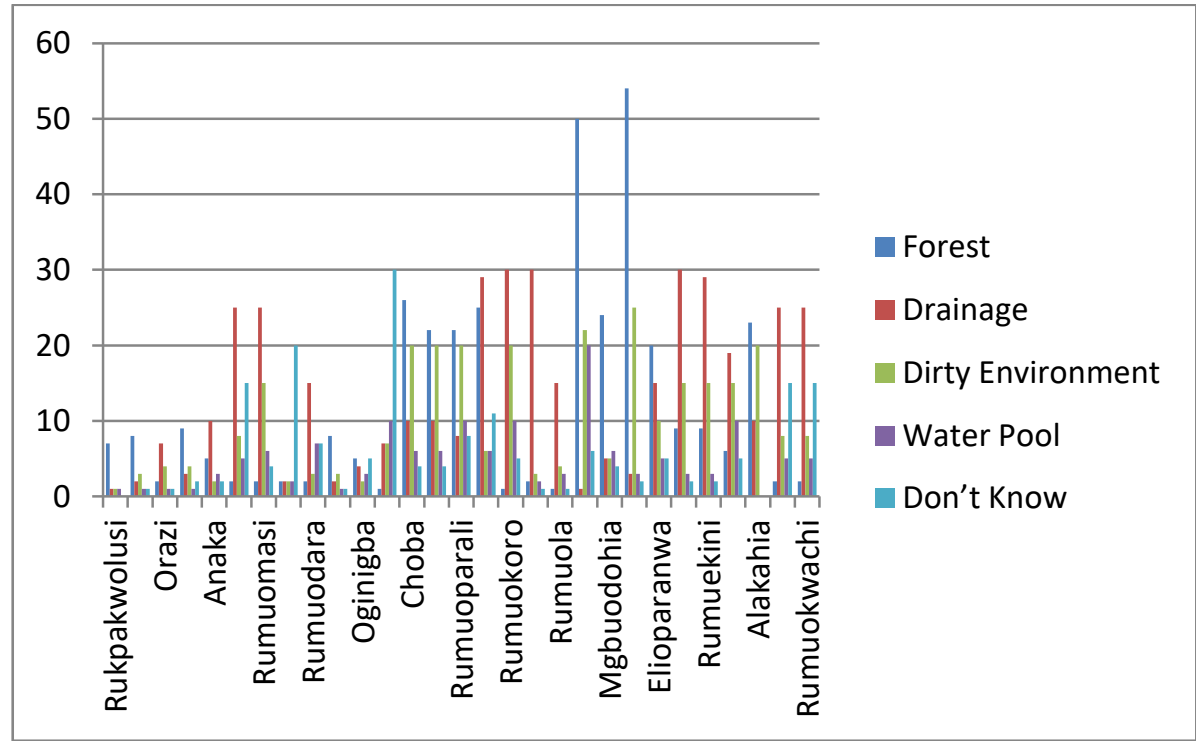

Figure 2 Respondent perception of breeding spots and sources of mosquitoes

From the analysis in figure 2, it is revealed 26 percent of respondent believe that malaria is caused by the presence of forest body, 29 percent is of the opinion that blocked drainage system result in the outbreak of malaria, 21 percent of the respondent are of the opinion that the nature of the environment to some extent determine the presence or absence of mosquitoes in the environment, 11 percent believed that pooling water in the environment creates an avenue for the breeding of mosquitoes and finally 13 percent cannot understand why there are still mosquitoes presence in their environment despite their efforts to contain them. That the presence of mosquitoes in their environment can be attributed to four major sources which are forest, blocked drainage, dirty environmental condition and stagnant pool. The majority of the respondent were of the opinion that the present of mosquitoes is made possible because of the presence of forest which serve as breeding sites for mosquitoes coupled with bad drainage and also dirty environmental conditions. Very few of the respondent attributed the spread of malaria to the breeding of mosquitoes in a stagnant pool while some handful of persons do not know the because of mosquitoes presence in their environment believing that the environment is neat and that the presence of mosquitoes is because it is peculiar to the Africa environment. 


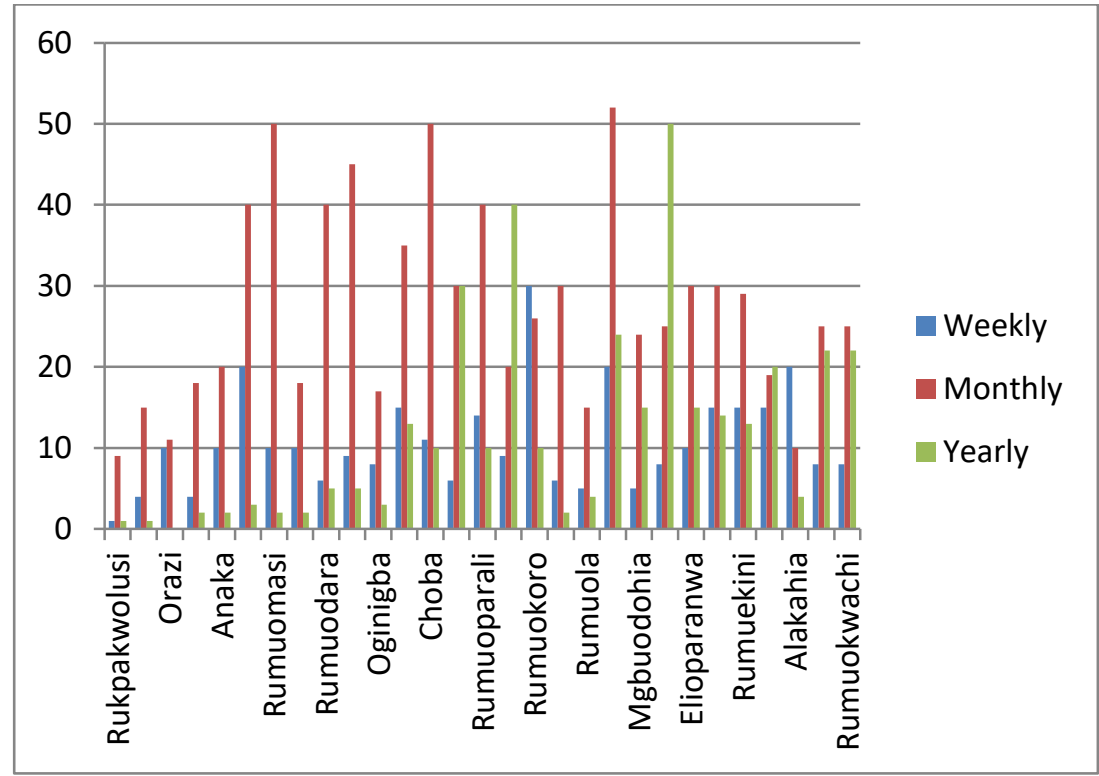

Figure 3 Occurrence of malaria parasite among Respondents

The respondents were of the opinion that the presence of mosquitoes in their environment has resulted in various ailment most especially malaria which is most occurring on a monthly basis in most of the respondents. The occurrence of malaria on a weekly basis is noticed among respondents residing mostly in rural communities while city dwellers complain of malaria on an annual base. From the analysis, 55 percent of respondents complain of malaria on a monthly basis, 24 percent on a yearly base while 21 percent had malaria reoccurrence on a weekly base.

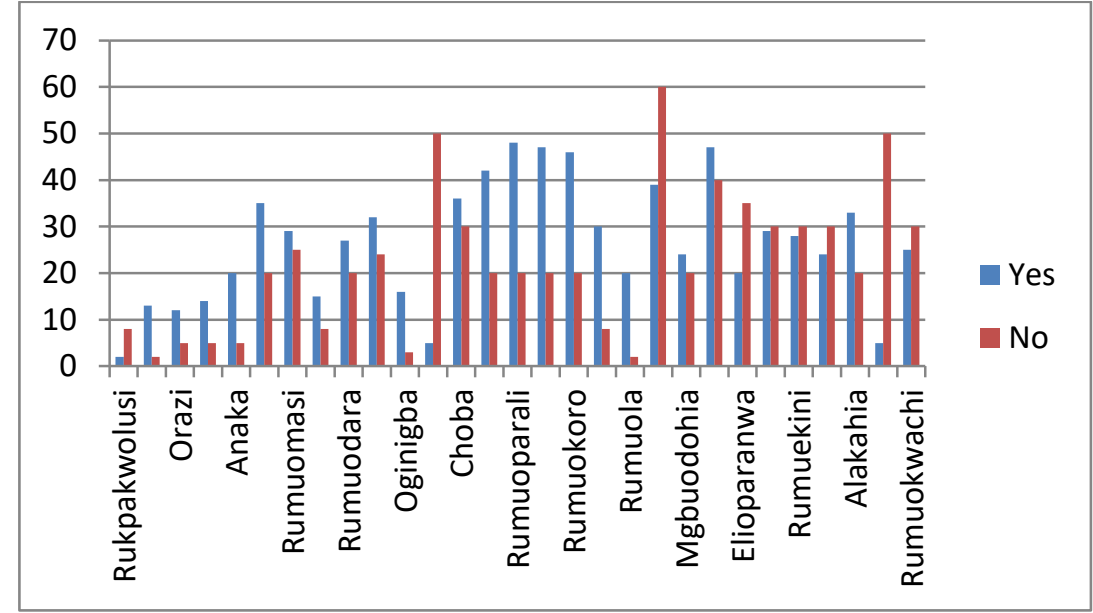

Figure 4 Respondent conduct of Laboratory Text in the wake of ailment

At the rise of ailment, respondents are left with the options to either conduct a test or not before embarking on treatment. From the analysis, 54 of the respondent conduct laboratory test on the causes of their ailment before drugs administration while 46 percent embark on drug administration without any test result as shown in figure 4 above. 


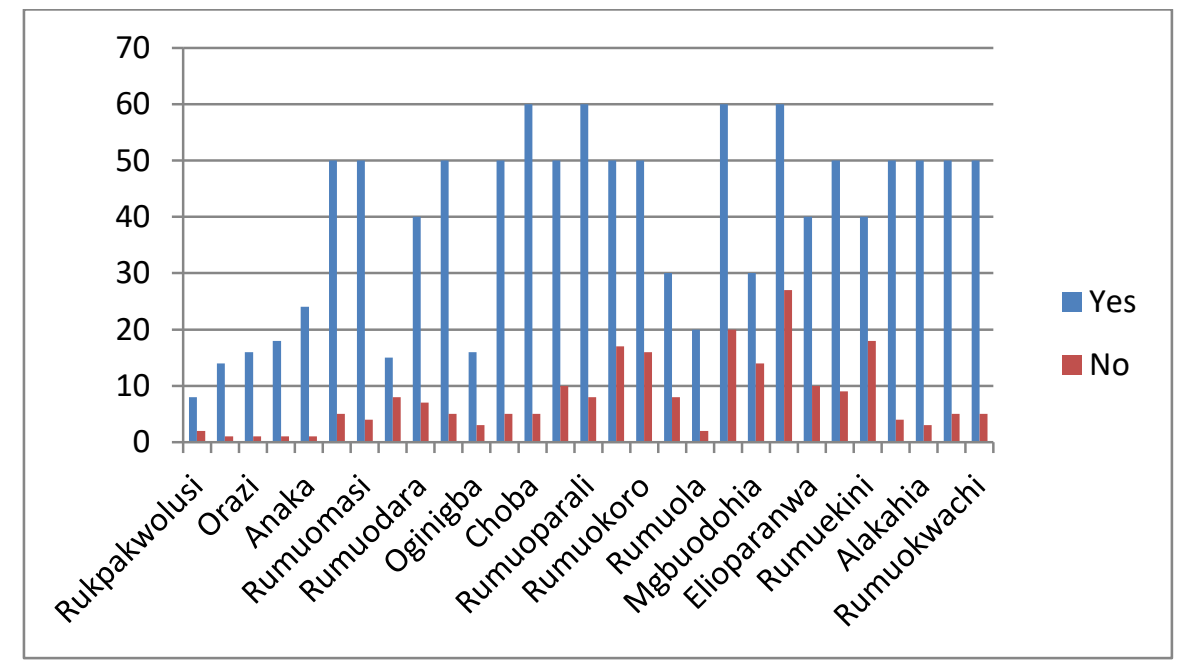

Figure 5 Efficiency of Awareness campaign in reducing malaria spread

From the analysis in table 5, 84 percent of the respondent believes that there has been an adequate awareness campaign in respect to malaria presence in the study area which 16 percent of the respondent claimed to be inadequately informed on the subject matter malaria. From the surface analysis of the local government, area shows that the relief of the study area is dominated by pockets of depression which allows the accumulation of water in the wake of rainfall exceeding excess from normal. This analysis became necessary in the wake of the respondent view on the frequent occurrence of malaria among them. This is as a result of elevation contribution to malaria spread as lower elevation tend to accumulate mosquitoes breeding sites in the study area as depressions have the tendency of accumulating water which serves as the breeding sites for mosquitoes larvae.

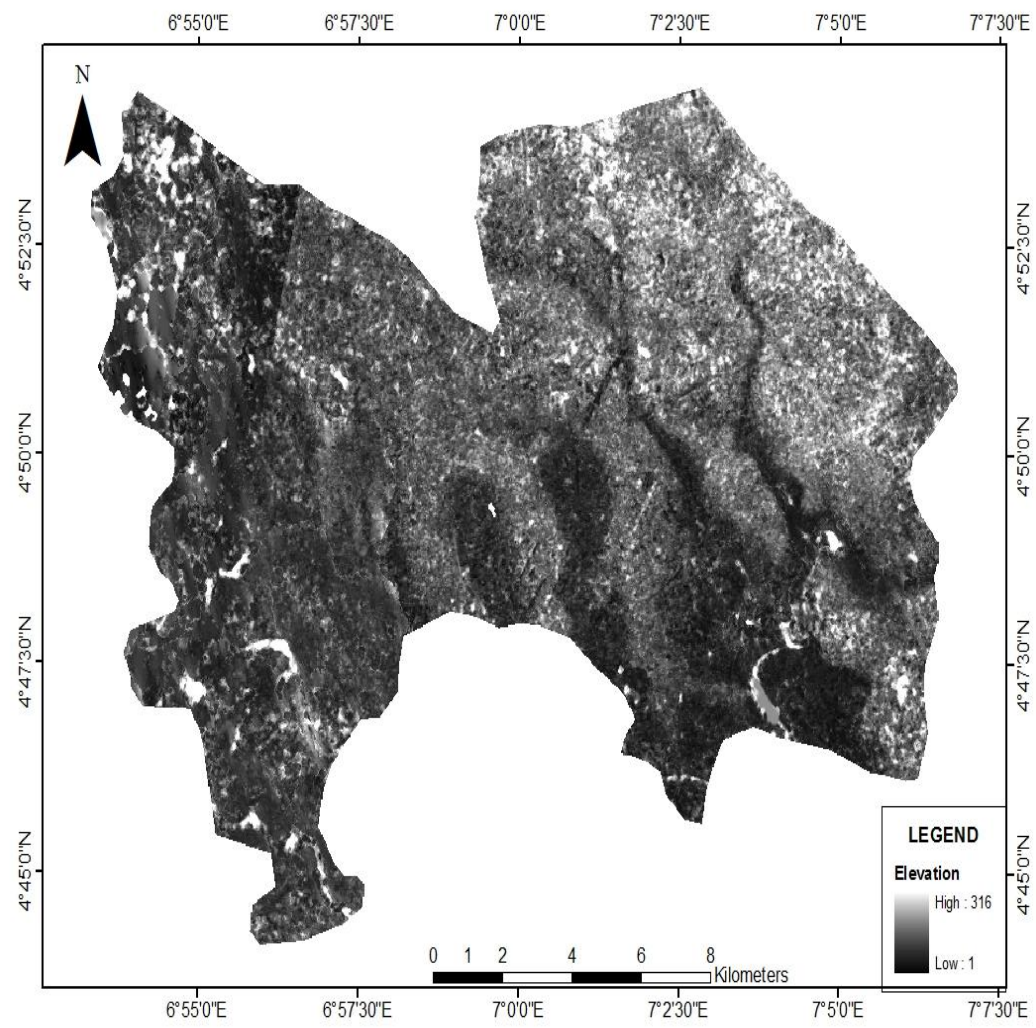

Figure 6 Digital Elevation Model of the Study Area

Figure 6 is the digital elevation model of the study area. It shows the area of depression in the study area. The darker area in the study area represents lower elevation hence avenue for water accumulation as shown in the legend of $1 \mathrm{~m}$ above sea level with a gradual rise to 316 meters above sea level. 


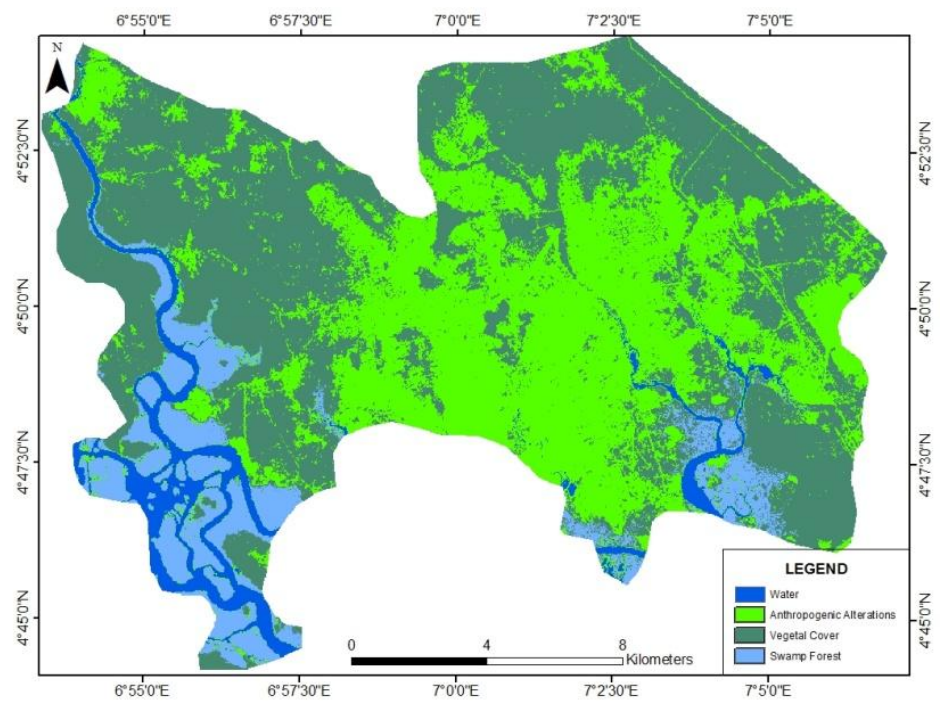

Figure 8 Classified Imagery of the study area

Figure 8 reveals the derivation from the classification of the imagery derived from Landsat over the study area. The analysis of the imagery allowed the classification of the study area into classes of water body, anthropogenic alterations, vegetal cover and swamp forest. This gives an idea of the nature of land cover over the study area and sees the relationship between the land cover, digital topographic map in the breeding and spread of mosquitoes within the study.

Table 1 Land Cover area Quantification of the study area

\begin{tabular}{|l|l|}
\hline Water & $14,662,559 \mathrm{~m}^{2}$ \\
\hline Swamp Forest & $25,149,099 \mathrm{~m}^{2}$ \\
\hline Forest & $133,936,276 \mathrm{~m}^{2}$ \\
\hline Built Up & $106,394,556 \mathrm{~m}^{2}$ \\
\hline
\end{tabular}

From the analysis of figure 8 , it was revealed that the study area is most dominated by forest cover which amounted to a total land cover of 133,936,276 meter square followed by built up area amounting to a tune of 106,394,556 meter square of surface coverage. Swamp forest account to $25,149,099$ meter square and surface water account to $14,662,559$ meter square of land area. With the presence of forest cover over 50 percent of the study area, there is room for the breeding of mosquito's larva at an alarming rate over the study area.

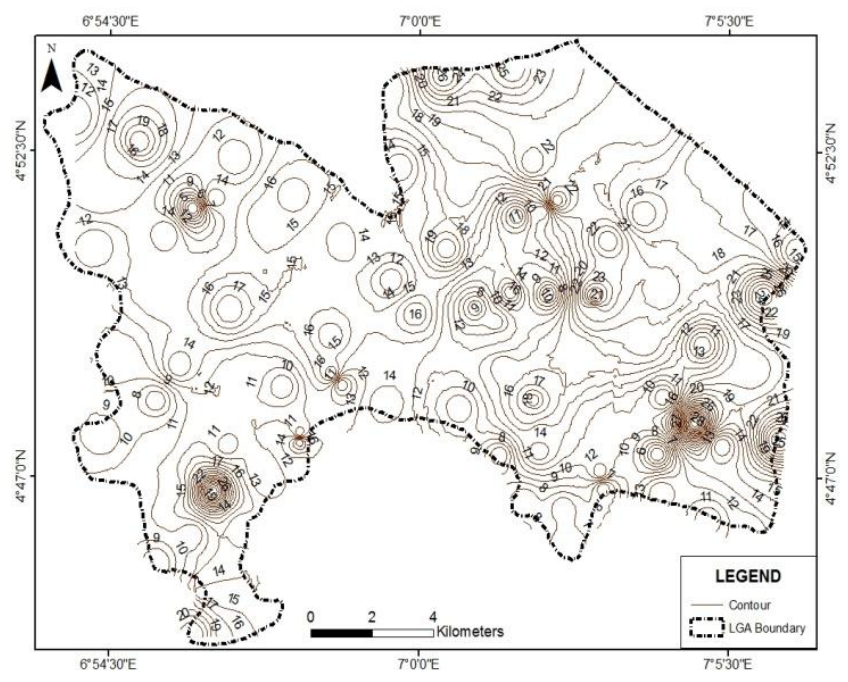

Figure 9 Contour Map of the Study Area 
The contour map of the study area shows that there are pockets of high rising elevation scattered across the study area surrounded by low lying area that would make for the meandering of supposed flowing water body hence resulting in a pocket of water pool across the study area which will favour the breeding of mosquitoes. The contour shows that the region could favour the stagnation of water in the surface which would favour the flourishing of mosquito's larvae across the study area and could be the potential causes of malaria spread within the study area with pockets of depressions shown in figure 10 .

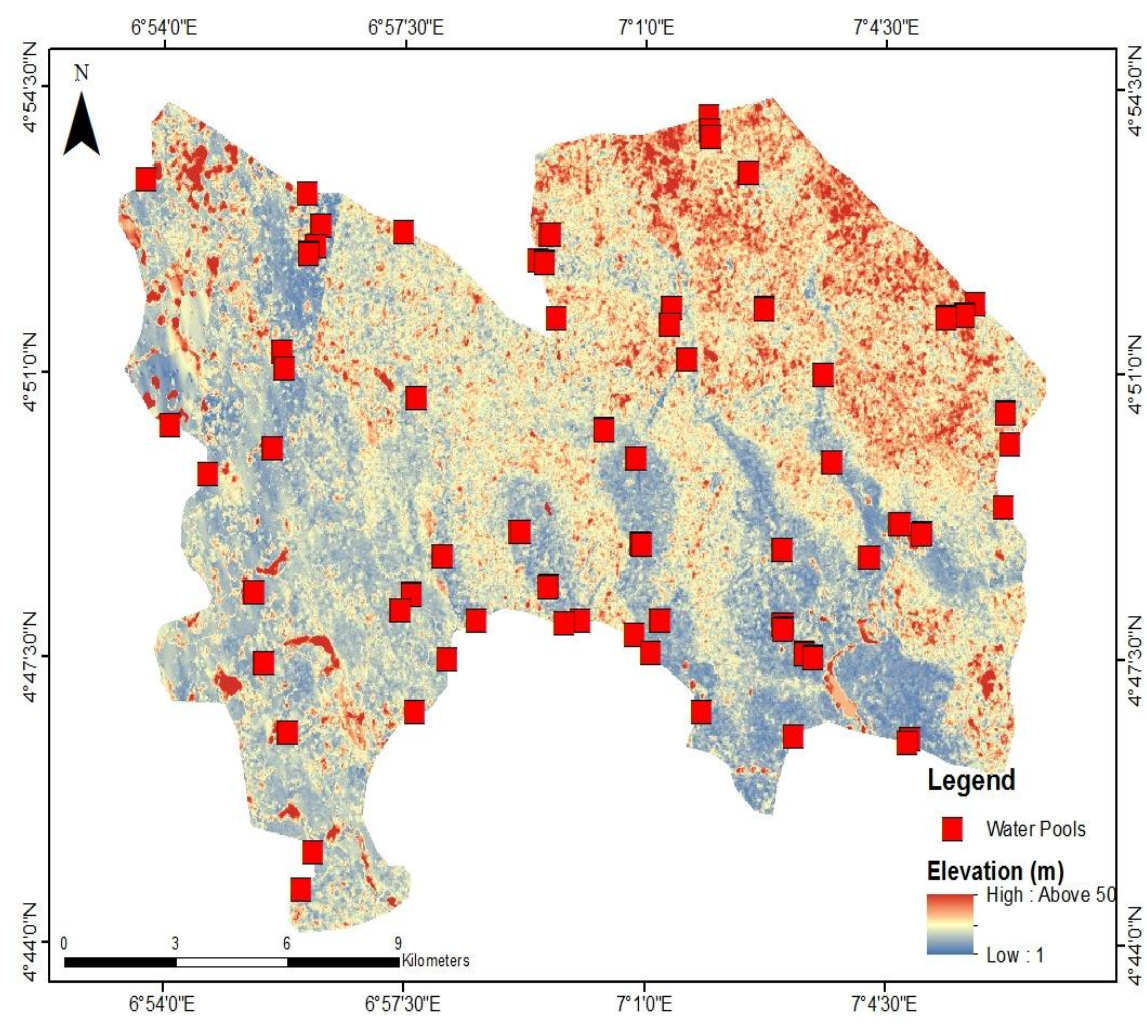

Figure 10 Potential Mosquitoes Breeding Sites of the Study Area

From the analysis, it is obvious that the potential breeding site cut across the entire study area as shown with the red coloured box spatially located across the study area. Analysis using the nearest neighbour tool reveals that the potential mosquitoes breeding sites across the study area were not random nor dispersed rather are clustered given the $\mathrm{z}$-score of -14.14 ; there is less than $1 \%$ likelihood that this clustered pattern could be the result of random chance.

\section{SUMMARY OF FINDINGS}

Findings revealed that most of the respondents interviewed acknowledged the presence of malaria in their locality. From the figure, over 90 percent of the respondents acknowledged the presence of mosquitoes in their locality. That the presence of mosquitoes in their environment can be attributed to four major sources which are forest, blocked drainage, dirty environmental condition and stagnant pool and that the presence of mosquitoes in their environment has resulted in various ailment most especially malaria which is most occurring on a monthly basis in most of the respondents. Most of the respondent do not conduct laboratory test before drug administration in the wake of ailment believing that there is already adequate awareness to identifying malaria as the major cause of their ailment. The DEM and image analysis of the study area reveal that the area is endowed with potential malaria breed in sites as a result of its topography. This has resulted in the clustered malaria breeding site across the study area.

\section{CONCLUSION}

From the analysis of result from the focal group discussion, the people believed that mosquitoes are prevalent in the study area and that the occurrence is as a resulting of the level of forest cover, drainages that are blocked and the nature and hygiene of the environment. Upon this is discovered that there are over 106 potential breeding sites for mosquitoes across the study area and the sites are clustered in the study area whose clustering is not attributed to chance.

\section{RECOMMENDATION}


This work recommends that efforts should be incorporated in environmental education aimed at educating the people of the use of treated nets in the wake of malaria outburst in the study area. Sanitation exercise should be enhanced will opening up of drain should be prioritized.

\section{REFERENCES}

[1] Aisuebeogun, A. (1995). Landforms Characteristics of the Environment. Journal of Geographic Thought.

[2] Gobo, A. E. (1990). Rainfall Data Analysis as an Aid for Designs for Maximum Drainage and Flow Control Works Port Harcourt. Journal of Discovery and Innovations, African Academy of Science Nairobi, Kenya., 2.

[3] Kingsley, O. O. (2002). Nigeria: Relief and Hydrography in Africa Atlases: Atlas of Nigeria. Lagos: Les Editions J.A.

[4] Mamman, A. B., Oyebanji, J. O., \& Petters, S. W. (2000). Nigeria: A People United, A Future Assured. Abuja: Millenium Edition, Gabumo Publishing. N.B.C. (2008). Annual Report.

[5] Oyegun, C. U., \& Adeyemo, A. (1999). Port Harcourt Region. Port Harcourt: Paragraphics. Winch et al (1997) Social and Cultural Factors Affecting Rate of Retreatment of

[6] Mosquito Nets with Insecticides in Bajamoyo District, Tanzania Tropical Medicine and International Health 2.

[7] Sexton J.O. (1994) Impregnated Bed nets for Malaria Control: Biological and Social Responsibility. American Journal of Tropical Medicine and Hygiene 50. Bruce-Chwatt L.J. et al (1980) The Rise and Fall of Malaria in Europe. Oxford University Press.

[8] Nevill C.G. (1990) Malaria in Sub-Saharan Africa. Social Science and Medicine, (6).Deobhankar R.B., Palkar N.D. (1990) Magnitude of DDT Resistance in Anophele Culicifacies in Maharastia State. Journal of Communicable Disease, 22 (1).

[9] Kristian H.H., Veronica H., Pramila V., (2003) The Behavioural and Social Aspect of Malaria and its control, UNDP/World Bank/WHO Special Programme Research and Training in Tropical Disease Volume 3

[10] Wongsrichanalai C., Pickard A. L., Werndorfer W. H., Meshnick S. R., (2002) Epidemiology of drug-resistant Malaria Lancet Infectious Diseases Volume 2.

[11] Zaim M., Gvillet P. (2002) Alternative Insecticide an Urgent Need Trend in Parasitology Volume 18.

[12] Kidson C., Indarata K. (1998) Ecology Economic and will: the vicissitude of MalariaStrategies in Asia. Parasitologia Volume 40.

[13] Sandosham A. A. (1959) Malariology with Special Reference to Malaya, Sigapore University of Malaya Press.

[14] Lactin D. J., Holiday N. J., Johnson D. L. and Craigen R. (1995) Improved RateModel forTemperature Dependent Development by Athropods Environment Entymology Volume 24.

[15] Bouma M.J., Sorndorp H.E., Van De Kaay H. J. (1994) Health and Climate Change the Lancet.Ceccato P., Connor S.J., Jeanne I. and Thompson M.C. (2005) Application of Geographical Information System and Remote Sensing Technologies for Assessing and Monitoring Malaria Risk. International Research Institute for Climate Protectio. The Earth Institute, Columbia University Palisade New York USA. 